\title{
Pagu: poesia, militância e condição feminina
}

Arlindo Rebechi Junior

Docente do Departamento de Ciências Humanas da Faculdade de Arquitetura, Artes e Comunicação (FAAC) da Universidade Estadual Paulista (Unesp), atuando em diversos cursos na graduação e no Programa de Pós-Graduação em Comunicação. Doutor em Literatura Brasileira pela Faculdade de Filosofia, Letras e Ciências Humanas da Universidade de São Paulo (FFLCH-USP).

E-mail: arlindo.rebechi@unesp.br

Resumo: Apresentação da poeta Patrícia Galvão, conhecida como Pagu, focalizando sua produção híbrida de poemas-desenhos (Álbum de Pagu) e o seu poema mais célebre, "Natureza morta", publicado sob o pseudônimo de Solange Sohl, em 1948.

Palavras-chave: poesia brasileira; modernismo brasileiro; Patrícia Galvão (Pagu).
Abstract: Presentation of the poet Patrícia Galvão, also known as Pagu, focusing her hybrid production of poem-drawings (Album de Pagu) and her most illustrious poem, "Natureza Morta" [Still Life], published in 1948 under the pseudonym Solange Sohl.

Keywords: Brazilian poetry; Brazilian Modernism; Patrícia Galvão (Pagu). 


\title{
comunicação \& educação • Ano XXIII • número 1 • jan/jun 2018
}

\author{
Outros se mataram. Outros foram mortos. Também passei por essa \\ prova. Também tentaram me esganar em muito boas condições. \\ Agora, saio de um túnel. \\ Tenho várias cicatrizes, mas ESTOU VIVA. \\ Patrícia Galvão, no panfleto político \\ Verdade e Liberdade (1950)
}

\section{PAGU, AS LETRAS E A CONDIÇÃO FEMININA}

Augusto de Campos, no seu recente texto de apresentação à reedição da obra de Patrícia Galvão (1910-1962), conhecida como Pagu, fez uma constatação muito apropriada: ainda que tivessem um papel decisivo, participativo e propositivo para as conquistas do campo literário nos primeiros decênios do século XX, muitas mulheres, intelectuais de primeira linha, tiveram, lamentavelmente, suas carreiras ofuscadas pela condição feminina de então. O processo de marginalização de várias intelectuais e escritoras foi, sem dúvida, sem fronteiras; ocorreu aqui e lá fora.

Dessa exclusão, Pagu se viu vítima, tal como suas contemporâneas inglesas, francesas e norte-americanas. Em um processo de recolocar a obra de Pagu em nova circulação e, portanto, de iniciar um real processo crítico de avaliação de suas realizações literárias, Augusto de Campos, crítico e poeta concreto cujo trabalho de reunião em Pagu: vida e obra ${ }^{1}$ é marco significativo desse esforço ${ }^{2}$, registra:

CAMPOS, Augusto de (org.). Pagu: vida e obra. São Paulo: Companhia das Letras, 2014.

2. Convém destacar que, desde os anos 1970, Augusto de Campos desempenha papel central na divulgação da obra de Patrícia Galvão. A come çar pela publicização do Álbum de Pagu na revista baiana Código, em 1975, e pela primeira antologia dos trabalhos da autora, na revista Através, em 1978. Posteriormente, Campos ainda publicou a edição Patrícia Galvão, Pagu: vida obra, em 1982 e 1987, pela editora Brasiliense.

3. CAMPOS, Augusto de. re-pagu. In: CAMPOS, op. cit., p. 12

4. Ibidem, p. 14

5. CAMPOS, Augusto de. pagu: amadora das artes. In: CAMPOS, op. cit., p. 57.
O fato é que, salvo na esmaecida imagem de estrela menor do anedotário do nosso modernismo, Patrícia Galvão mal existia nos anos 1950, quando Oswald ainda era "tabu" no cânone das nossas universidades. E assim perdurava trinta anos depois, à luz dos rígidos critérios acadêmicos. ${ }^{3}$

Coube a Augusto de Campos, tal como fizera com Oswald em circunstâncias de outrora, colocar a obra e a vida de Pagu em evidência nos fins dos anos 1970. Como ele mesmo disse, era preciso "remitificar Pagu" ao mesmo tempo em que era urgente desmistificá-la: caberia "enfatizar não a face superficial de sua atividade, mas a densidade maior de sua aventura intelectual"4. E completa o crítico, no que parece ser uma síntese precisa para definir os rumos e o lugar de Pagu nas letras nacionais:

Não se trata de forjar uma escritora ou uma artista. Patrícia Galvão foi uma e outra coisa, sem propriamente fazer carreira de letras ou de artes. Assim como foi poeta, sem o ser em termos profissionais, se de profissão se pode falar a respeito de poesia. Amadora em artes. Amadora de artes. Trata-se de recuperar a imagem de uma rebelde da vida e das artes, de captar as fulgurações intermitentes mas lúcidas de uma personalidade rara, dentre as poucas que lutaram por manter acesa a chama do inconformismo que, a partir de 1922, incandesceu o nosso provinciano ambiente cultural. ${ }^{5}$ 


\section{PAGU ENTRE MODERNISTAS}

Ainda em seus ambientes escolares, o primeiro contato de Pagu com os nomes do modernismo deu-se aos 15 anos. Na mesma época conheceu Guilherme de Almeida, então secretário da Escola Normal do Brás, e avistou Mário de Andrade, sem todavia estabelecer um contato mais próximo com ele, no Conservatório Dramático e Musical de São Paulo, em circunstâncias nas quais ela e colegas não presumiam que "o poeta era o poeta, que o professor fosse outra coisa" ${ }^{6}$. O escritor de Macunaíma apresentava-se tão somente como um sujeito "de riso de criança grande"

Foi, todavia, apenas em 1928, aos 18 anos, que Pagu consegue estreitar laços com artistas modernistas, mais precisamente com os nomes que gravitavam em torno do casal Tarsila e Oswald, em suas animadas reuniões no casarão da Alameda Barão de Piracicaba. A essa altura Oswald já nutria, gulosamente, as rusgas com Mário de Andrade, e a Revista de Antropofagia, em sua fase denominada "Segunda Dentição", apontava um novo encaminhamento crítico e programático para parte do grupo de primeira geração de modernistas.

Dada uma documentação ainda fragmentada, formada por lances artísticos, contribuições em jornais e periódicos lacunares (muitas delas talvez ainda a serem coletadas por pesquisadores de sua obra) e por momentos de suas práticas políticas, o nome de Pagu ainda carece ser mais bem avaliado no contexto de atuação do modernismo brasileiro. Augusto de Campos, em uma entrevista de 1982 a Mario Sérgio Conti, nos chama atenção para a questão:

É bom lembrar que ela era contemporânea em idade de escritoras, como, por exemplo, a Raquel de Queiroz e Dinah Silveira de Queirós e apenas dois anos mais velha do que Nelson Rodrigues e Jorge Amado. Na verdade, Patrícia foi dos poucos remanescentes do modernismo que permaneceram fiéis aos ideais revolucionários do movimento no tocante à renovação da linguagem artística, quando a maioria ou se academizou ou se arrependeu. ${ }^{8}$

Dentro desse novo contexto, entre idas e vindas oriundas da participação ativa e militante no grupo Tarsila-Oswald, Pagu iniciou suas colaborações na Revista de Antropofagia, nessa segunda fase, quando o periódico começa a ser publicado no Diário de São Paulo, em 1929. Sua primeira contribuição foi um desenho. Desde aqueles tempos, Pagu já manifestava sua grande admiração por Tarsila, o que se refletia, de certa forma, em sua dedicação ao desenho, em traços e estilo notadamente herdados da grande pintora modernista. É conhecida a declaração de Pagu sobre a artista, em 1929, na ocasião da exposição do seu quadro Abaporu, no Rio de Janeiro: "com Tarsila fico romântica. Dou por ela a última gota do meu sangue. Como artista só admiro a superioridade dela" ${ }^{9}$.

Nessa mesma matéria sobre a cobertura da exposição de Tarsila do Amaral no Rio de Janeiro, Pagu, que acompanhava a comitiva paulista de artistas em visita à capital brasileira de então, também tem seu destaque e projeção. Clovis de Gusmão, responsável pela reportagem, solicita à Pagu que recite algum
6. GALVÃO, Patrícia. Depois de amanhã Mário de Andrade [crônica no Diário de São Paulo, em 23 fev. 1947]. In: CAMPOS, op. cit., p. 200.

7. Ibidem.

8. CAMPOS, Augusto de. A verdade de Pagu. Entrevista a Mario Sergio Conti. In: CAMPOS, op. cit., p. 69-70.

9. GUSMÃO, Clóvis de. $\mathrm{Na}$ exposição de Tarsila [Revista Para Todos, em 3 ago. 1929]. In: CAMPOS, op. cit., p. 109. 
poema. Prontamente, a jovem de 18 anos atende ao pedido, sob aplausos de Álvaro Moreyra, Aníbal Machado, Oswald de Andrade, Eugenia Álvaro Moreyra e da própria Tarsila do Amaral:

\author{
No meu quintal tem uma laranjeira \\ aquela mesma \\ onde brincamos na noite de Natal \\ no meu quintal tem um pessegueiro \\ com flores cor de rosa \\ onde chupei-te a boca \\ pensando que era fruta. \\ no galinheiro tem oito galinhas, \\ um pato, um ganso e um pinto. \\ no galinheiro fiz um arranha-céu \\ com latas de gasolina. \\ E fiz com paus de vassoura \\ estacas para os cravos. \\ meu quintal é uma cidade!... \\ De frangos, postes, luz e arranha-céu. \\ E para simbolizar o seu progresso, \\ desafiando triunfal, \\ tem a bandeira de uma calça rendada no varal. ${ }^{10,11}$
}

O poema de Pagu, um dos seus primeiros trabalhos a ser publicizado dentro do grupo de modernistas, dá mostras de sua verve, a um só tempo, provocativa e sem travos amargos, beirando em alguns momentos o tom brincalhão. Entre a representação do mundo rural e o desejo da cidade, as imagens formuladas pela jovem poeta apreendem desde a ingenuidade dos primeiros momentos da infância - marcada pelas flores, árvores e bichos soltos - até o que nos parece mais radical em sua aventura poética: o desejo da crítica e da compreensão de um outro mundo, muito mais político, emulado pela cidade instaurada na brincadeira infantil, que já revela o seu progresso mais perturbador: "meu quintal é uma cidade!”.

10. GALVÃOapudGUSMÃO, op. cit., p. 109-110.

11. Foi realizada a atualização ortográfica do poema. Ao que tudo indica, este seria parte dos anunciados Sessenta poemas censurados, uma reunião de textos de Pagu que nunca foram encontrados.

12. CAMPOS, Augusto de. eh pagu eh. CAMPOS, op. cit., p. 94.

\section{PAGU E O SEU ÁLBUM POÉTICO}

A admiração e a ligação de Pagu com a grande pintora modernista Tarsila e com o poeta Oswald fariam a jovem artista investir, de maneira bastante eclética, em uma criação que conjugasse o gosto pelo desenho e pela produção de poemas, resultando em um conjunto textual conhecido como Álbum de Pagu. Ao que tudo indica, são produções realizadas entre os seus 18 e 19 anos. Trata-se de um trabalho bastante original e, conforme Augusto de Campos ressaltou, "não se pode dar ao luxo de ignorar coisas como essa com gosto de invenção e de liberdade"12. 
A manutenção dos desenhos e dos poemas de Pagu, que são dedicados à Tarsila do Amaral, deve-se à guarda destes pela pintora. Entre 1929 e a década de 1970, a crítica especializada não obteve acesso ao material, até que José Luís Garaldi o encontra entre os documentos de Tarsila, guardados pelo sobrinho da pintora. Sua primeira divulgação pública, atenta e bem documentada, deve-se à iniciativa de Augusto de Campos, que publica os poemas na revista Código, em $1975^{13}$, e na revista Através, em $1978^{14}$.

De maneira bastante livre e cheia de invenção, esse conjunto de poemas e desenhos, que totalizam 28 croquis, revelam lances de uma autobiografia livre e poética, conforme o material se autodenomina: Pagú nascimento vida paixão $e$ morte. Essencialmente, são ilustrações justapostas aos poemas que ofertam aos seus leitores uma profusão de ideias sobre o mundo e sobre a própria persona de Pagu, num tom e numa dicção que a colocam como uma representante autêntica dessa fração de modernistas antropofágicos. Comecemos pelos croquis números IV e V (Figura 1), que representam o seu próprio nascimento:
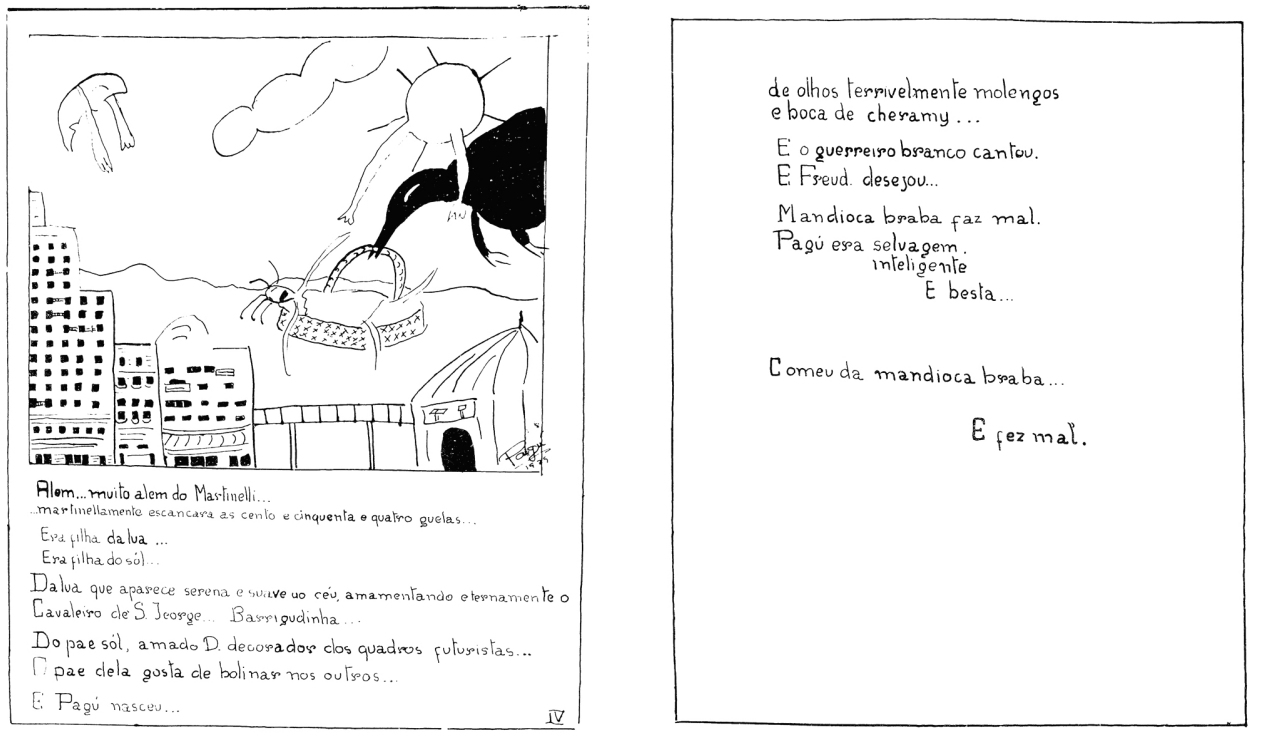

Figura 1: Croquis IV e $\mathrm{V}^{15}$

No poema-desenho, linguagem verbal e não verbal se completam num evidente jogo de intermedialidade. A referência inicial é o gigantismo arquitetônico do Edifício Martinelli, o arranha-céu recém-inaugurado na capital paulista. Após evidente demarcação de uma grande espacialidade ("muito além do Martinelli”), abre-se o poema para o dado mítico da origem de Pagu. Sua origem é grandiosa, como filha do sol e da lua, reforçada pela imagem introduzida pelo substantivo modificado, que se transforma em advérbio de intensidade ("martinellamente"). Convém notar que o recurso utilizado pela poeta é a via paródica ("Além... muito além do Martinelli... / ...martinellamente escancarava as cento e cinquenta e quatro guelas... / [...] E Pagu nasceu"16); em termos comparativos, cabe lembrar o início do segundo capítulo de Iracema, de José de Alencar: "Além, muito além daquela serra, que ainda azul no
13. CÓDIGO. Salvador: [s.n.], n. 2, 1975.

14. ATRAVÉS. São Paulo: [s.n.], n. 2, 1978.

15. GALVÃO, Patrícia. Pagú nascimento vida paixão e morte. Código, Salvador, n. 2,1975, p. 26.

16. Ibidem, p. 26 
horizonte, nasceu Iracema"17. Todavia, o caso de Pagu não é de um nascimento qualquer; demarca-se nele o humor característico de uma certa poética modernista: "o pai dela gosta de bolinar nos outros...", e nasce Pagu, com "olhos terrivelmente molengos / e bocas de cheramy"18 - referência a um perfume importado dos anos 1920.

Por fim, na parte final desse primeiro poema, Pagu é cantada pelo guerreiro branco, desejada por Freud, alertada de que "mandioca braba faz mal", mas "Pagu era selvagem / inteligente / E besta". E conclui de forma irreverente e irônica: "Comeu mandioca braba... E fez mal" ${ }^{19}$.

No plano visual, é possível de imediato notar imagens antropomórficas do sol e da lua. Pagu, tal como o anti-herói Macunaíma, chega à cidade urbanizada e cheia de prédios. Talvez não seja exagero sugerir, pela imagem formulada, uma Pagu como metonímia da transformação e do progresso, espécie de sopro juvenil de renovação, de uma vida insubordinada e cheia de ousadia.

Da segunda parte desse álbum, chamada de "vida", é significativo seu croqui número XI (Figura 2):

17. ALENCAR, José de. Iracema: lenda do Ceará. São Paulo: Companhia das Letras, 2016. p. 17

18. GALVÃO, op. cit., p. 26

19. Ibidem, p. 26.

20. Ibidem, p. 28.

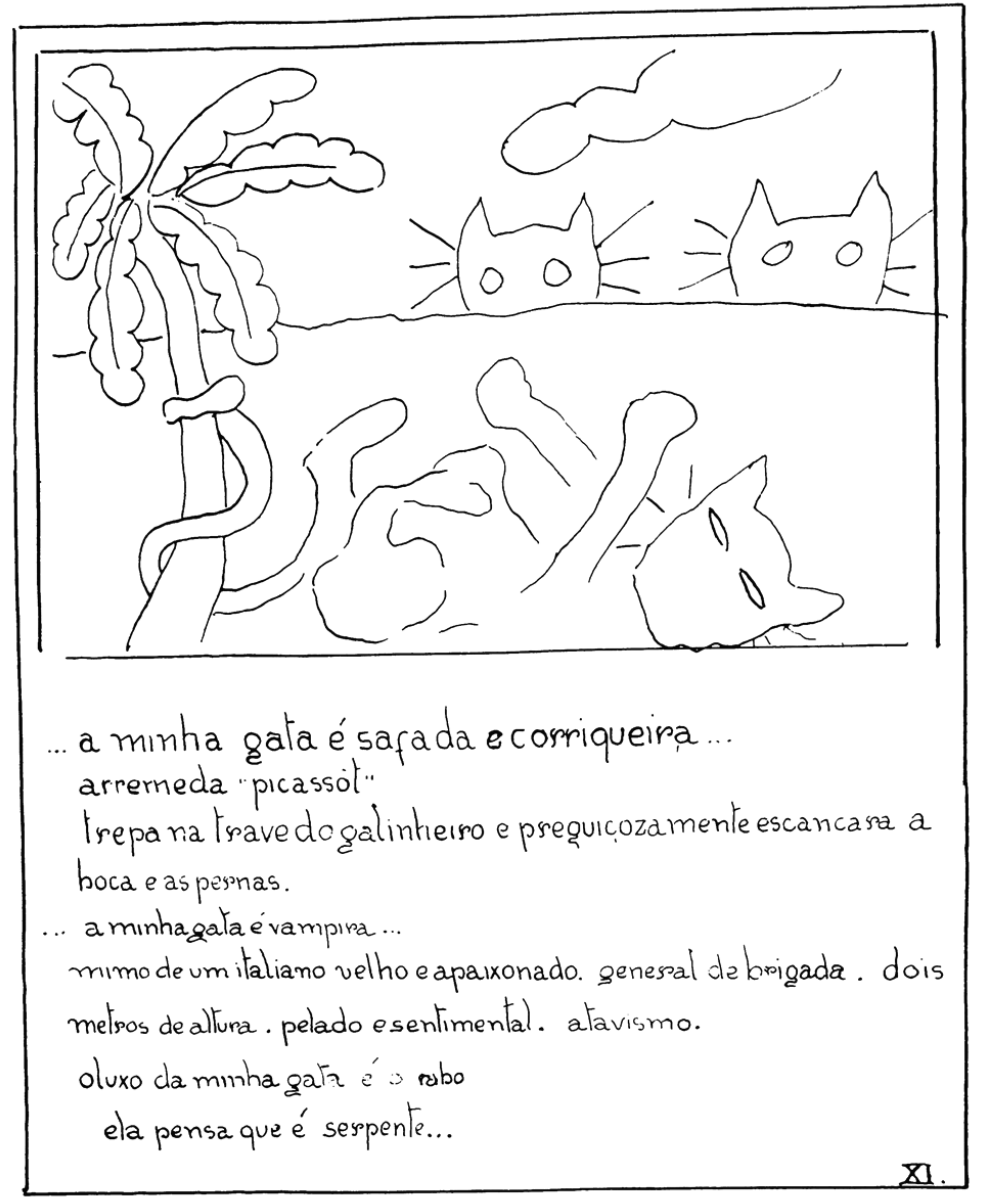

Figura 2: Croqui IV e V ${ }^{20}$ 
Se pensarmos no tempo e nas circunstâncias em que foi produzido, este poema-desenho de Pagu é um dos mais ousados do conjunto. Sua sensualidade é marcante, o que o faz ultrapassar o âmbito corriqueiro e prosaico da história de um animal de estimação. Os contornos trazidos por sua escrita cifrada mais o campo de atuação visual do desenho, ambos repletos de ambiguidades, sugerem uma inovadora abordagem sobre a sexualidade e sobre a liberdade do corpo feminino, muito à frente do seu tempo.

Analisando o conjunto desses croquis de Pagu, talvez seja possível compará-los, em que pese os diferentes gêneros em jogo, ao mesmo estilo fragmentário, telegráfico, à apresentação de personagens na forma de mosaico e à composição por justaposição em episódios das Memórias sentimentais de João Miramar (1924), de Oswald de Andrade. Augusto de Campos faz o seguinte balanço crítico a respeito do Álbum de Pagu:

A marca de Oswald e de Tarsila é evidente, tanto mais ao se ter em vista que o Primeiro Caderno do aluno de poesia Oswald de Andrade, com desenhos do poeta e capa de Tarsila, é de 1927. Mas a eleição de tais influências pela jovem Pagu já é um ato de discernimento e de sensibilidade fora do comum. Por amadorísticos que se mostrem os seus desenhos, na insegurança do traço e na ingenuidade ou no "kitsch" modernista de certas soluções, o Álbum é, ainda assim, espantoso como ideia e como realização. A linguagem ao mesmo tempo descontraída e econômica de textos e ilustrações é atrevida para o seu tempo e, ainda hoje, cheia de vitalidade. ${ }^{21}$

\section{SOLANGE SOHL, PSEUDÔNIMO DE PATRÍCIA GALVÃO}

Ao longo de sua trajetória intelectual, Pagu cultivou o uso extensivo de pseudônimos, seja dentro da prática jornalística ou dentro da prática literária. Exemplo notório é o seu livro Parque industrial: romance proletário (1933), no qual o uso do pseudônimo Mara Lobo se deve a uma exigência do Partido Comunista (PC). Ou ainda o caso de seus contos policiais publicados nos anos 1940, na revista Detective, sob o pseudônimo de King Shelter, que só foram descobertos mais de 50 anos depois.

Uma hipótese viável, no caso de Pagu, para a utilização recorrente de inúmeros pseudônimos pode estar ligada à sua prática política, com atuação e militância extremamente progressistas. É sabido que até mesmo o envolvimento de Oswald de Andrade na militância política nos anos 1930, em parte, se deve aos estímulos vindos da escritora.

Na vida de Pagu, o ano de 1948 traz dois fatos importantes quanto à sua atuação no mundo da poesia. Em maio daquele ano, Patrícia Galvão participa do Congresso de Poesia, em São Paulo. Meses depois, mais precisamente em 15 de agosto de 1948, ela publica no suplemento literário do Diário de São Paulo o seu poema mais conhecido, "Natureza Morta", sob o pseudônimo de Solange Sohl.

21. CAMPOS, Augusto de. pagu: amadora das artes. In: CAMPOS, op. cit., p. 59. 
comunicação \& educação • Ano XXIII • número 1 • jan/jun 2018

Cabe trazermos o poema em questão:

\section{Natureza Morta}

Os livros são dorsos de estantes distantes quebradas.

Estou dependurada na parede feita um quadro.

Ninguém me segurou pelos cabelos.

Puseram um prego em meu coração para que eu não me mova

Espetaram, hein? a ave na parede

Mas conservaram os meus olhos

É verdade que eles estão parados

Como os meus dedos, na mesma frase.

As letras que eu poderia escrever

Espicharam-se em coágulos azuis.

Que monótono o mar!

Os meus pés não dão mais um passo.

$\mathrm{O}$ meu sangue chorando

As crianças gritando,

Os homens morrendo

O tempo andando

As luzes fulgindo,

As casas subindo,

O dinheiro circulando,

O dinheiro caindo.

Os namorados passando, passeando,

Os ventres estourando

O lixo aumentando,

Que monótono o mar!

Procurei acender de novo o cigarro.

Por que o poeta não morre?

Por que o coração engorda?

Por que as crianças crescem?

Por que este mar idiota não cobre o telhado das casas?

Por que existem telhados e avenidas?

Por que se escrevem cartas e existe o jornal?

Que monótono o mar!

TatVÃ Patrícia. Solange Sohl/1948. In: CAMPOS, op. cit., p. 235.

23. Junto ao poema havia uma nota editorial que dizia o seguinte: "Solange Sohlé uma estreante. A publicação do presente poema é feita a título de animação, pois há que considerar, na sua realização lírica embebida de um dramatismo intenso, um compromisso para o futuro".
Estou espichada na tela como um monte de frutas apodrecendo.

$\mathrm{Si}$ eu ainda tivesse unhas

Enterraria os meus dedos nesse espaço branco

Vertem os meus olhos uma fumaça salgada

Este mar, este mar não escorre por minhas faces.

Estou com tanto frio, e não tenho ninguém...

Nem a presença dos corvos.

SUARÃO, PRAIA GRANDE ${ }^{22,23}$ 
Como mais tarde Geraldo Ferraz veio registrar, sendo ele o revelador do mistério de Solange Sohl/Patrícia Galvão, "Natureza Morta" talvez tenha chamado a atenção de muitos jovens à época pela sua intensidade de poesia maldita, cheia de angústias, amargores e uma incontornável dissolução daquilo que pode parecer absoluto. Nesse sentido, o poema aprofunda a psicologia de um suposto eu lírico e impregna a realidade com seus elementos oníricos. O resultado bastante feliz é um conjunto de imagens significativas da relativização da consciência desse eu: "Os livros são dorsos"; "Estou dependurada na parede feita um quadro"; "Puseram um prego em meu coração"; "Espetaram, hein? a ave na parede" 24 .

Em "Natureza morta", é possível supor como eu lírico um tipo de poeta que aguarda, murmurando, a própria morte. O contraste é bastante nítido nas contraposições, marcadas na segunda estrofe, entre o movimento do mundo, próprio das ações que ocorrem ("gritando", "andando", "morrendo", "subindo", "circulando", "caindo", "passando" etc.), e a monotonia da poeta: "os meus pés não dão mais um passo / O meu sangue chorando" 25 .

Está assimilada à própria estrutura do poema essa vida fragmentada, sentida e pensada pela experiência da persona poeta. Não se trata de apenas uma aderência temática a um campo de imagens sobre as desilusões do pós-guerra, mas de mostrar que a construção fragmentada, similar a um fluxo de consciência e característica marcante desse poema, é reveladora de uma nova experiência e de um novo estado de ânimo. As perguntas existenciais, por assim dizer, formuladas na terceira estrofe são exemplos precisos desse recurso. Isso a que temos acesso é apenas uma parcela microscópica da vida psíquica desse perturbado eu. Nada em absoluto. O que se projeta talvez resulte de uma nova experiência da própria personalidade humana, sobremaneira caótica e em constante fluxo. É uma experiência de alguém que viveu as vicissitudes do século XX, seja nas suas dimensões estético-artísticas, seja nas dimensões da vida social.

Como o propósito deste texto é tão somente uma breve apresentação dos fragmentos poéticos deixados por Pagu, cabe finalizá-lo com o que se supõe ser o seu último texto publicado em vida. Isso é válido pela sua força e intensidade de poema e por reafirmar uma estrutura poética que procura, incessantemente, os significados mais profundos para a situação do indivíduo moderno, diante de um sistema produtivo sem precedentes. Trata-se do poema "Nothing", publicado em 23 de setembro de 1962 em A Tribuna, de Santos:

Nothing

Nada nada nada

Nada mais do que nada

Porque vocês querem que exista apenas o nada

Pois existe o só nada 
comunicação \& educação • Ano XXIII • número 1 • jan/jun 2018

Um para-brisa partido uma perna quebrada

O nada

Fisionomias massacradas

Tipoias em meus amigos

Portas arrombadas

Abertas para o nada

Um choro de criança

Uma lágrima de mulher à toa

Que quer dizer nada

Um quarto meio escuro

Com um abajur quebrado

Meninas que dançavam

Que conversavam

Nada

Um copo de conhaque

Um teatro

Um precipício

Talvez o precipício queira dizer nada

Uma carteirinha de travel's check

Uma partida for two nada

Trouxeram-me camélias brancas e vermelhas

Uma linda criança sorriu-me quando eu a abraçava

Um cão rosnava na minha estrada

Um papagaio falava coisas tão engraçadas

Pastorinhas entraram em meu caminho

Num samba morenamente cadenciado

Abri o meu abraço aos amigos de sempre

Poetas compareceram

Alguns escritores

Gente de teatro

Birutas no aeroporto

E nada. ${ }^{26}$

\section{REFERÊNCIAS BIBLIOGRÁFICAS}

ALENCAR, José de. Iracema: lenda do Ceará. São Paulo: Companhia das Letras, 2016.

ATRAVÉS. São Paulo: [s.n.], n. 2, 1978.

CAMPOS, Augusto de (org.). Pagu: vida e obra. São Paulo: Companhia das Letras, 2014.

A verdade de Pagu. Entrevista a Mario Sergio Conti. In: (org.). Pagu:

vida e obra. São Paulo: Companhia das Letras, 2014. 
Pagu: poesia, militância e condição feminina - Arlindo Rebechi Junior

. eh pagu eh. (org.). Pagu: vida e obra. São Paulo: Companhia das Letras, 2014.

- pagu: amadora das artes. In: (org.). Pagu: vida e obra. São

Paulo: Companhia das Letras, 2014. . re-pagu. In: (org.). Pagu: vida e obra. São Paulo: Companhia das Letras, 2014.

CÓDIGO. Salvador: [s.n.], n. 2, 1975.

GALVÃO, Patrícia. Depois de amanhã Mário de Andrade [crônica no Diário de São Paulo, em 23 fev. 1947]. In: CAMPOS, Augusto de (org.). Pagu: vida e obra. São Paulo: Companhia das Letras, 2014.

Pagú nascimento vida paixão e morte. Código, Salvador, n. 2, p. 24-34, 1975 .

- poemas/1960-62. In: CAMPOS, Augusto de (org.). Pagu: vida e obra. São Paulo: Companhia das Letras, 2014.

Solange Sohl/1948. In: CAMPOS, Augusto de (org.). Pagu: vida e obra. São Paulo: Companhia das Letras, 2014.

GUSMÃo, Clóvis de. Na exposição de Tarsila [Revista Para Todos, em 3 ago. 1929]. In: CAMPOS, Augusto de (org.). Pagu: vida e obra. São Paulo: Companhia das Letras, 2014. 
